\title{
Fever and arthralgia as the initial symptoms of primary bone marrow diffuse large B-cell lymphoma: A case report
}

\author{
SAISAI REN ${ }^{1,2^{*}}$, YANLING TAO $^{3 *}$, LU JIA $^{2},{\text { PANPAN } \text { CHENG }^{2}, \text { JILEI ZHANG }^{2} \text { and HAO ZHANG }}^{2}$ \\ ${ }^{1}$ Graduate School, Jining Medical University, Jining, Shandong 272000; Departments of ${ }^{2}$ Hematology and ${ }^{3}$ Pediatrics, \\ Affiliated Hospital of Jining Medical University, Jining, Shandong 272129, P.R. China
}

Received February 7, 2015; Accepted March 1, 2016

DOI: $10.3892 / \mathrm{ol} .2016 .4405$

\begin{abstract}
Primary bone marrow diffuse large B-cell lymphoma (DLBCL) is rare, and only a few cases have been reported. Fever and arthralgia as the initial symptom are extremely rare; however, awareness must be made of this presentation. The current study describes the clinical and pathological findings of a 41-year-old man affected by fever and arthralgia. Blood tests revealed leukopenia and anemia. Multiple bone marrow biopsies were conducted and confirmed the diagnosis of primary bone marrow DLBCL. Primary bone marrow DLBCL is a rare and frequently misdiagnosed subset of non-Hodgkin's lymphoma. The current case demonstrates that utility of bone marrow biopsy for diagnosis should not be ignored, and that repeated bone marrow punctures in multiple locations may be necessary.
\end{abstract}

\section{Introduction}

Primary bone marrow diffuse large B-cell lymphoma (DLBCL) is an uncommon type of non-Hodgkin's lymphoma (NHL). DLBCL may involve nodal or extranodal sites (1); however, initial presentation in the bone marrow occurs infrequently (2-6). Extranodal involvement of the bone marrow as an isolated and unique localization of aggressive NHLs has been reported (7), including cases of anaplastic large cell lymphoma or DLBCL.

The rapid diagnosis of primary bone marrow DLBCL is challenging, as the clinical symptoms and signs are nonspecific. In addition, the clinical features, optimal management, diagnostic procedures and prognostic factors associated with this disease remain to be elucidated (8). Recently, the diagnostic

Correspondence to: Professor Hao Zhang, Department of Hematology, Affiliated Hospital of Jining Medical University, 89 Guhuai Road, Jining, Shandong 272129, P.R. China

E-mail: gx-zhanghao@126.com

*Contributed equally

Key words: bone marrow biopsy, fever, arthralgia, diffuse large B-cell lymphoma criteria for primary bone marrow lymphoma (PBML) have been proposed, and the clinicopathological features of this extremely rare tumor have also been documented (7). The current study presents the case of a patient with primary bone marrow DLBCL who was admitted to the hospital with symptoms of fever and arthralgia. A correct initial diagnosis of primary bone marrow DLBCL was determined by multiple bone marrow biopsies at different locations.

\section{Case report}

A 41-year-old male patient was admitted to the Affiliated Hospital of Jining Medical University (Jining, China) on August 4th, 2014, with initial complaints of a high fever and arthralgia. The patient also presented with recent onset of pharyngalgia, coughing, weight loss and malaise. Following admission, a physical examination revealed that the patient's body temperature was $39.4^{\circ} \mathrm{C}$; however, lymphadenopathy and hepatosplenomegaly were not observed. Blood tests indicated leukopenia and anemia [white blood cell (WBC) count, $2.75 \times 10^{9} / 1$ (normal, 3.5-9.5 $\left.\times 10^{9} / 1\right)$; red blood cell (RBC)

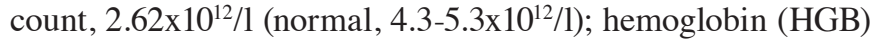
level, $100 \mathrm{~g} / 1$ (normal, 130-175 g/l)], elevated lactate dehydrogenase (LDH) levels (1,191 U/1; normal, 90-240 U/1) and elevated C-reactive protein (CRP) levels (39.83 mg/l; normal, 0-10 mg/l). All other results, including comprehensive serology and screening for autoimmune antibodies, were unremarkable. A bone marrow puncture of the right posterior iliac crest was a dry tap. No abnormalities were detected (data not shown). Contrast-enhanced computed tomography (CT; SOMATOM Definition Flash CT; Siemens Healthcare, Erlangen, Germany) confirmed no hepatosplenomegaly, and malignancy could not be confirmed.

In the following week, pancytopenia, LDH elevation, direct bilirubin elevation, CRP elevation and B symptoms were not resolved. These results indicated no lymph node and extranodal involvement, but suggested bone marrow involvement. Bone marrow aspiration was repeated in the left posterior iliac crest and sternum, and a bone marrow biopsy of the left posterior iliac crest was performed. Resected tissues were formalin-fixed, paraffin-embedded and cut into sections (2-4 $\mu \mathrm{m})$ using a RM2235 rotary microtome (Leica, Wetzlar, Germany). Peripheral blood samples and bone marrow aspirate smears were stained with Wright-Giemsa (Beijing 
A

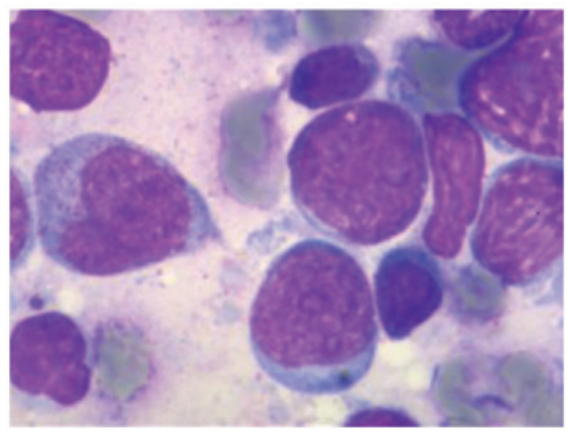

B

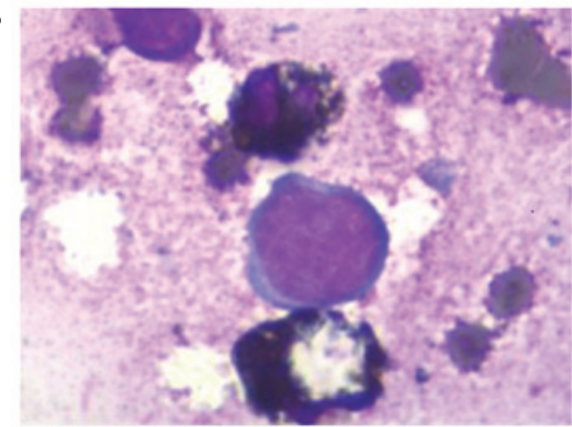

Figure 1. Bone marrow biopsy smears. Large lymphoma cells were present in the marrow aspirates: (A) Wright-Giemsa staining and (B) leukocyte peroxidase (myeloperoxidase) staining (magnification, $\mathrm{x} 1,000)$.

A
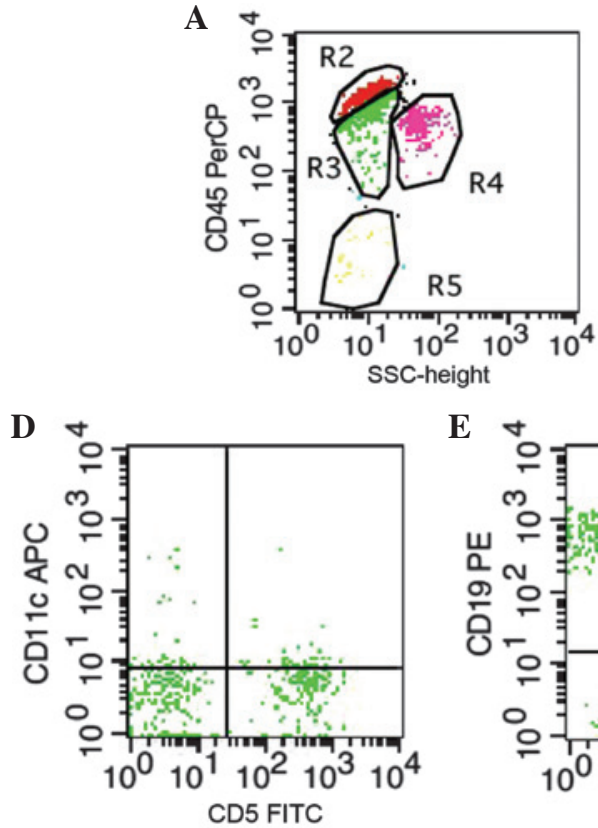

B

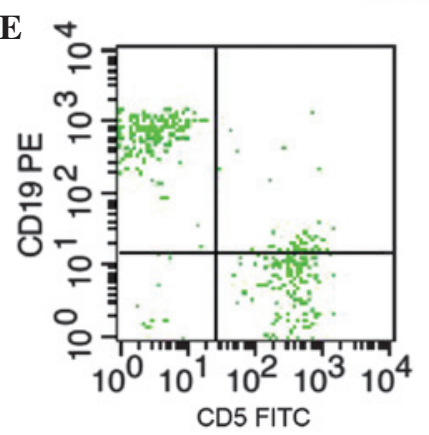

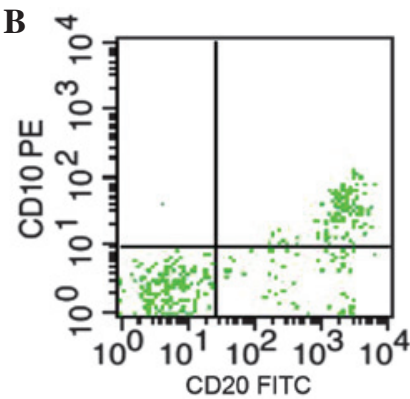

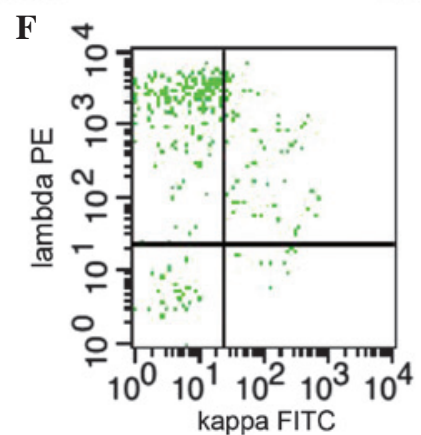

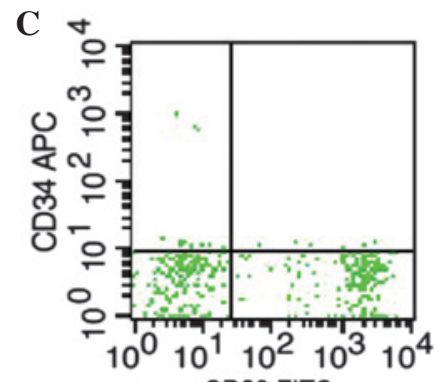

$\mathrm{CD} 20 \mathrm{FITC}$

Figure 2. Immunophenotype of the bone marrow cells as detected by flow cytometric analysis. (A) CD45 was used to gate B lymphocytes. (B-G) Cells were positive for (B, C and G) CD20 (positive rate $>20 \%$ ), (B) CD10, (E) CD19 and (F) $\lambda$ light chain, and negative for (D) CD11c, (D and E) CD5 and (G) $\kappa$ light chain. CD, cluster of differentiation; FITC, fluorescein isothiocyanate; PE, phycoerythrin; APC, allophycocyanin; SSC, side scatter.

Leagene Biotech Co., Ltd., Beijing, China) for morphological evaluation (Olympus L100 S600; Olympus, Tokyo, Japan). Formalin-fixed specimens were stained with hematoxylin and eosin (Beyotime Institute of Biotechnology, Shanghai, China) for histological evaluation. Large lymphoma cells were present in the marrow aspirates on Wright-Giemsa-stained (Fig. 1A) and leukocyte peroxidase (myeloperoxidase)-stained (Fig. 1B) slides.

For flow cytometry, $50 \mu \mathrm{l}$ aliquots of cell suspensions were incubated at room temperature $\left(22-25^{\circ} \mathrm{C}\right)$ with the following fluorescent monoclonal mouse anti-human antibodies (BD Biosciences, San Jose, CA, USA) for 30 min: Cluster of differentiation (CD)45-peridinin-chlorophyll protein complex (cat. no. 564106), CD10-phycoerythrin (PE; cat. no. 561002), CD20-fluorescein isothiocyanate (FITC; cat. no. 556632), CD34-allophycocyanin (APC; cat. no. 560940), CD11c-APC (cat. no. 559877), CD5-FITC (cat. no. 561896), CD19-PE (cat. no. 561741) and immunoglobulin $\kappa$ (cat. no. 555861) and $\lambda$ (cat. no. 562893) light chains. Next, $2.5 \mathrm{ml}$ ammonium chloride (BD Biosciences) was added for $10 \mathrm{~min}$ to lyse the
RBCs. The cells were centrifuged at $190 \mathrm{x}$ g for 5 min using the Cence H1650R centrifuge (Cence, Changsha, China) and washed with phosphate-buffered saline. The second cell pellet was resuspended in $0.5 \mathrm{ml}$ PBS containing $1 \%$ formaldehyde (Polysciences Inc., Warrington, PA, USA). Cells were analyzed using a FACSCalibur flow cytometer (BD Biosciences). Data were quantified using CellQuest software (BD Biosciences). Flow cytometry confirmed the presence of lymphoma in the aspirates, which revealed positivity for cluster of differentiation (CD)20, CD19, CD10 and $\lambda$ light chain, and negativity for CD5, CD11c and $\kappa$ light chain (Fig. 2).

Biopsy specimens revealed focal hyperplasia of large abnormal lymphoid cells and bone marrow necrosis (Fig. 3A-B). Bone marrow biopsy specimens were formalin-fixed, paraffin-embedded and cut into $2-4-\mu \mathrm{m}$ sections using the RM2235 rotary microtome. Each section was stained with hematoxylin and eosin and used for immunostaining. Immunohistochemical analyses were performed using an autostainer (Benchmark XT system; Ventana Medical Systems, Inc., Tucson, AZ, USA) according to the manufacturer's 
A

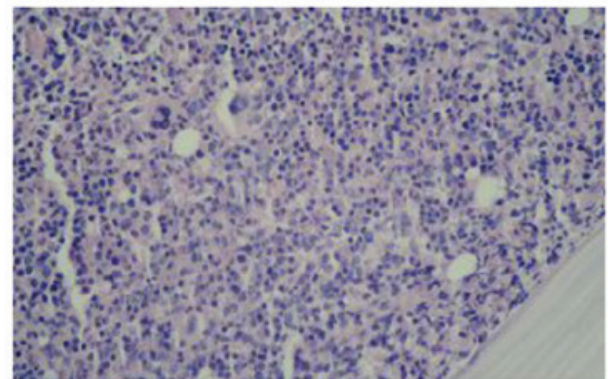

C

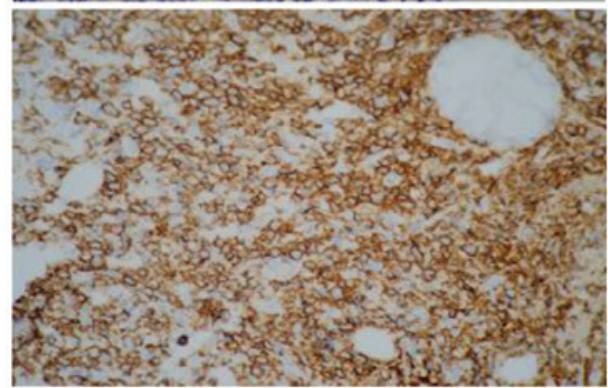

$\mathbf{E}$

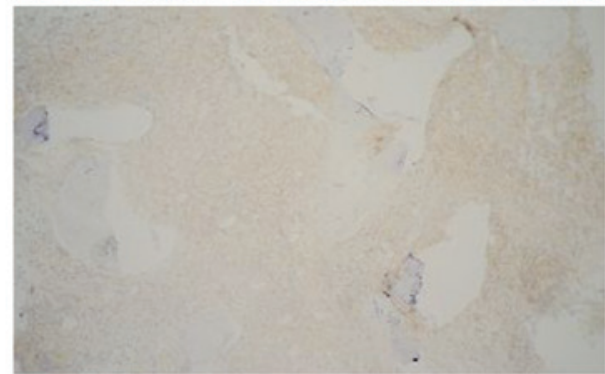

G

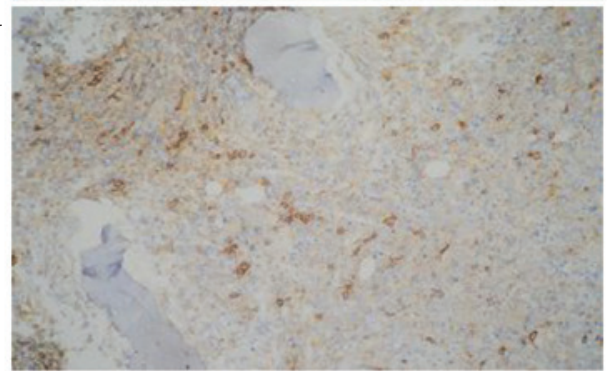

I

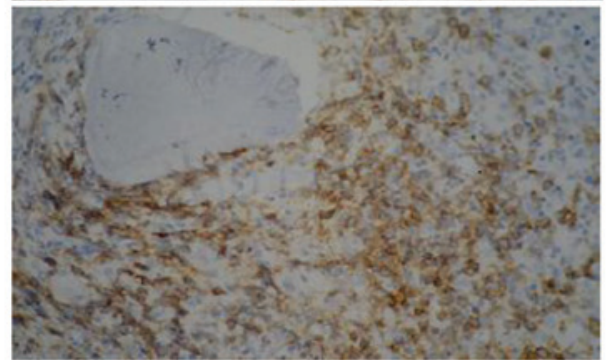

K

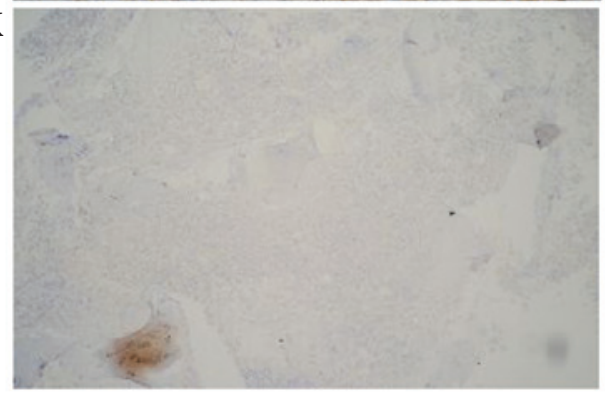

B

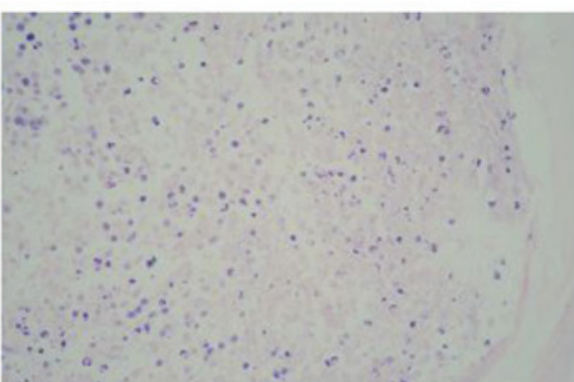

D

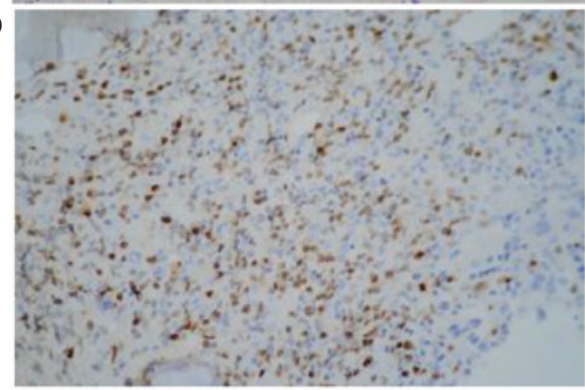

$\mathbf{F}$

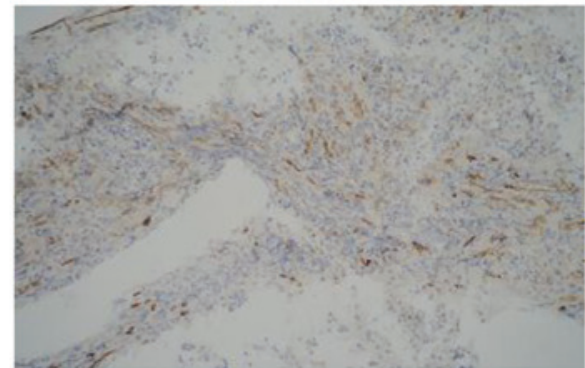

H

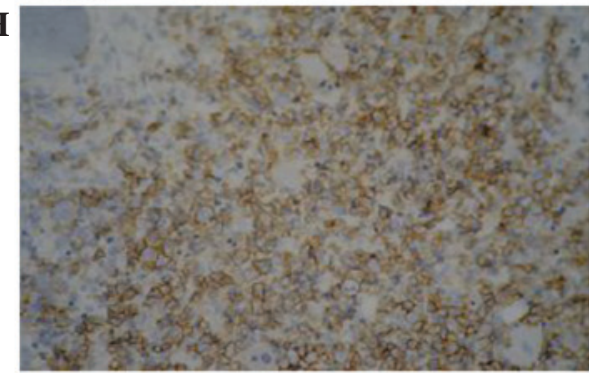

$\mathbf{J}$

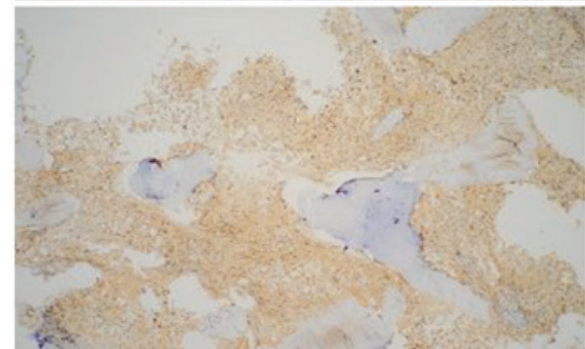

L

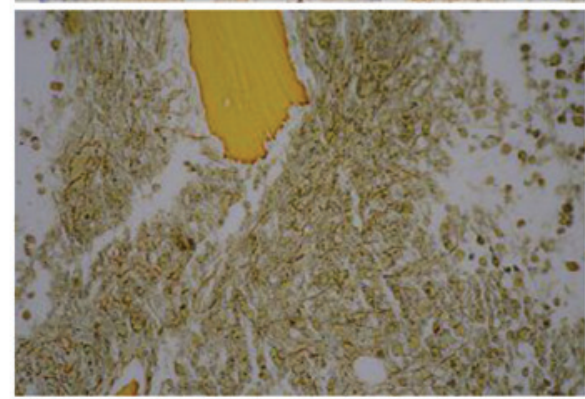

Figure 3. Histopathological and immunohistochemical features of the bone marrow biopsy. Images of the bone marrow biopsy showed involvement of large abnormal lymphoid cells with focal clusters. (A) Hyperactivity of the bone marrow (hyperplasia) and (B) necrotic zone (hematoxylin and eosin staining; magnification, $\mathrm{x} 400$ ). The tumor cells were (C) positive for CD20 (magnification, $\mathrm{x} 400$ ), (D) positive for melanoma associated antigen (mutated) 1 (magnification, $\mathrm{x} 400$ ), (E) negative for CD10 (magnification, $\mathrm{x} 100$ ), (F) negative for CD34 (magnification, $\mathrm{x} 200$ ), (G) negative for CD38 (magnification, $\mathrm{x} 200$ ), (H) negative for CD43 (magnification, x400), (I) positive for CD79a (magnification, x400), (J) positive for Ki-67 (magnification, x100), (K) negative for terminal deoxynucleotidyl transferase (magnification, x100), and (L) positive for silver staining (magnification, $\mathrm{x} 400$ ). CD, cluster of differentiation. 
protocol. The following ready-to-use mouse monoclonal primary antibodies were used: CD43 (cat. no. 14690602), CD10 (cat. no. 14368806), CD20 (cat. no. 140316020), CD38 (cat. no. 141124341), terminal deoxynucleotidyl transferase (cat. no. 140508197), Ki67 (cat. no. 14690209) and CD79a (cat. no. 14620803) (ZSGB-BIO, Beijing, China); and CD34 (cat. no. END-R-7-CE; Leica). Following incubation with the primary antibodies at $4^{\circ} \mathrm{C}$ overnight, sections were incubated with a monoclonal biotin-conjugated goat anti-mouse IgG secondary antibody (cat. no. Kit-9710; ready-to-use; Fuzhou Maixin Biotech. Co., Ltd., Fuzhou, China) at $37^{\circ} \mathrm{C}$ for $30 \mathrm{~min}$, followed by peroxidase-labeled streptavidin and diaminobenzidine chromogen (Ventana UltraView Universal DAB Detection Kit; Ventana Medical Systems, Inc.). Evaluation was then performed using an Olympus BX51 microscope (Olympus Corporation, Tokyo, Japan). All immunostaining was performed using a BenchMark XT automated immunostaining device (Ventana Medical Systems, Inc.). Immunohistochemical staining indicated that the abnormal cells were positive for CD20, melanoma associated antigen (mutated) 1, CD79a, Ki-67 and silver staining; and negative for CD10, CD34, CD38, CD43 and terminal deoxynucleotidyl transferase (Fig. 3C-L). This immunophenotype matches that previously ascribed to DLBCL (9). A diagnosis of primary bone marrow DLBCL was made based on these results.

In August 2014, the patient was administered with four cycles of chemotherapy with cyclophosphamide, vincristine, epirubicin and prednisone (CHOP regimen) plus etoposide as part of a 3-week standard cycle, as follows: Etoposide [50 $\mathrm{mg} /\left(\mathrm{m}^{2} \mathrm{x}\right.$ day $\left.)\right]$, vincristine $\left[0.4 \mathrm{mg} /\left(\mathrm{m}^{2} \mathrm{x}\right.\right.$ day $\left.)\right]$ and epirubicin $\left[15 \mathrm{mg} /\left(\mathrm{m}^{2} \mathrm{x}\right.\right.$ day $\left.)\right]$ administered via continuous intravenous (i.v.) drip for $96 \mathrm{~h}$; cyclophosphamide $\left(750 \mathrm{mg} / \mathrm{m}^{2}\right.$, i.v., day 5); and prednisone [60 $\mathrm{mg} /\left(\mathrm{m}^{2} \mathrm{x}\right.$ day), orally, days 1-5]. Cerebrospinal fluid examination showed no obvious lymphomatous infiltration (data not shown). Following one course of chemotherapy, remission of symptoms was observed. The patient's temperature returned normal, and the arthralgia reduced. Blood tests indicated a WBC count of $6.10 \times 10^{9} / 1$, RBC count of $2.37 \times 10^{12} / 1$ and HGB level of $67 \mathrm{~g} / 1$, and the bone marrow tests indicated partial remission. If the patient achieved complete remission, another two cycles of $\mathrm{CHOP}$ chemotherapy would be administered as consolidation therapy. If not, other chemotherapy regimens would be explored. The last follow-up was conducted on May 7, 2015, however, the patient has since been lost to follow-up.

\section{Discussion}

Extranodal DLBCLs have specific clinicopathological features that are dependent on the organ of origin (3). Previous reports have shown that invasion of lymphoma cells may be detected in the brain, adrenal glands, kidney and skin in autopsy cases (10-17). However, DLBCL primarily arising from the bone marrow is an extremely rare entity, with only a few retrospective studies and sporadic cases reported in the literature (4,18-22). Previously, Wong et al (23) reported 14 cases of large cell lymphoma with initial manifestation in the bone marrow, of which 4 exhibited a B-cell phenotype, 3 a T-cell phenotype, and 1 a non-T non-B phenotype. The majority of patients had 'swinging' fever and peripheral blood cytopenia.
However, in the present case, the patient complained only of fever and arthralgia as the initial symptoms. This presentation is extremely rarely reported.

The diagnosis of primary bone marrow DLBCL is difficult due to the absence of guidelines regarding clinical features, optimal management, diagnostic procedures and prognostic factors (8). As no lesions were observed in the present case, and only fever and joint pain were reported, multiple bone marrow biopsies in different locations were performed. DLBCL is most commonly diagnosed using positron emission tomography (PET)-CT $(24,25)$. By contrast, the current study relied on multiple bone marrow biopsies combined with the clinical findings, physical examination, morphology and flow cytometry results. The findings of the present case corresponded to the diagnostic criteria of PBML previously proposed (7). Notably, the patient in the present case complained primarily of joint pain. This may have resulted from bone marrow necrosis. However, this should be studied further.

The optimal therapy for PBML has still not been proposed. Autologous hematopoietic stem cell transplantation or multi-agent chemotherapy with rituximab plus CHOP regimen followed by involved field radiotherapy are typically the chosen treatment options (17,26-29). However, the exact roles and effects of these treatments are unclear due to the extremely low incidence of the disease. In the present study, the patient received CHOP regimen plus etoposide, and achieved a reduction in the fever and arthralgia, in addition to partial remission as indicated by bone marrow tests.

In conclusion, DLBCL primarily arising from the bone marrow is an extremely rare entity. The present case demonstrates that awareness should be raised of bone marrow DLBCL, particularly in patients presenting with fever and arthralgia. In addition, when lymphoma is suspected, it is imperative to perform multiple bone marrow biopsies in various locations. The long-term outcome and the prognosis of DLBCL require further investigation with more cases.

\section{Acknowledgements}

This study was supported by the Science and Technology Program of Shandong Province, China (grant no. 2012YD18066) and the Health and Family Planning Commission of Shandong Province (grant no. 9,2012).

\section{References}

1. Yamashita T, Ishida M, Moro H, Yumoto H, Uchibayashi S, Yoshii M, Nakanishi R, Okuno H, Yoshida T, Okuno T, et al: Primary bone marrow diffuse large B-cell lymphoma accompanying cold agglutinin disease: A case report with review of the literature. Oncol Lett 7: 79-81, 2014

2. Morice WG, Rodriguez FJ, Hoyer JD and Kurtin PJ: Diffuse large B-cell lymphoma with distinctive patterns of splenic and bone marrow involvement: Clinicopathologic features of two cases. Mod Pathol 18: 495-502, 2005.

3. Mann RB: Are there site-specific differences among extranodal aggressive B-cell neoplasms? Am J Clin Pathol 111 (1 Suppl 1): S144-S150, 1999.

4. Lapa C, Knott M, Rasche L, Herrmann K, Buck AK and Rosenwald A: Primary bone marrow diffuse large B-cell lymphoma affecting distal parts of the legs as a cause of persisting B symptoms. Eur J Haematol 93: 545-546, 2014.

5. Ogura K, Miyake N, Yasuda H, Udaka N and Hirano T: Diffuse large B-cell lymphoma initially manifesting in bone marrow: A case report. Rinsho Byori 58: 1176-1180, 2010 (In Japanese). 
6. Antic D, Petrovic N, Pelemis M, Stevanovic G, Perunicic M and Mihaljevic B: 'Invisible' primary cutaneous diffuse large B-Cell lymphoma, leg type, as a cause of fever of unknown origin. J Clin Oncol 31: e276-e279, 2013.

7. Martinez A, Ponzoni M, Agostinelli C, Hebeda KM, Matutes E, Peccatori J, Campidelli C, Espinet B, Perea G, Acevedo A, et al: Primary bone marrow lymphoma: An uncommon extranodal presentation of aggressive non-Hodgkin lymphomas. Am J Surg Pathol 36: 296-304, 2012.

8. Jiang AG, Gao XY and Lu HY: Diagnosis and management of a patient with primary pulmonary diffuse large B-cell lymphoma: A case report and review of the literature. Exp Ther Med 8: 797-800, 2014.

9. Menon MP,Pittaluga S and Jaffe ES: The histological and biological spectrum of diffuse large B-cell lymphoma in the World Health Organization classification. Cancer J 18: 411-420, 2012.

10. Oehler E, Valour F, Hachulla E and Ghawche F: Myopericarditis as the presenting manifestation of adult Still's disease. Rev Med Interne 35: 827-830, 2014 (In French).

11. Imamura K, Awaki E, Aoyama Y, Kondo S, Horie Y, Ohama E and Nakashima K: Intravascular large B-cell lymphoma following a relapsing stroke with temporary fever: A brain biopsy case. Intern Med 45: 693-695, 2006.

12. Lokesh KN, Sathyanarayanan V, Kuntegowdanahalli CL, Suresh TM, Dasappa L and Kanakasetty GB: Primary diffuse large B-cell lymphoma of testis: A single centre experience and review of literature. Urol Ann 6: 231-234, 2014.

13. Kashimura M, Noro M, Akikusa B, Okuhara A, Momose S, Miura I, Kojima M and Tamaru J: Primary splenic diffuse large B-cell lymphoma manifesting in red pulp. Virchows Arch 453: 501-509, 2008

14. Kim HS: Primary testicular diffuse large B-cell lymphoma: A case report focusing on touch imprint cytology and a non-germinal center B-cell-like phenotype. Exp Ther Med 6: 33-36, 2013.

15. Zhang X, Sun M, Zhang L and Shao H: Primary hepatosplenic CD5-positive diffuse large B-cell lymphoma: A case report with literature review. Int J Clin Exp Pathol 6: 985-989, 2013.

16. Kodama K, Massone C, Chott A, Metze D, Kerl H and Cerroni L: Primary cutaneous large B-cell lymphomas: Clinicopathologic features, classification, and prognostic factors in a large series of patients. Blood 106: 2491-2497, 2005.

17. Al Shemmari S, Sankaranarayanan SP and Krishnan Y: Primary mediastinal large B-cell lymphoma: Clinical features, prognostic factors and survival with RCHOP in Arab patients in the PET scan era. Lung India 31: 228-231, 2014.

18. Níainle F, Hamnvik OP, Gulmann C, Bermingham C, Kelly J, Mc Evoy P and Murphy P: Diffuse large B-cell lymphoma with isolated bone marrow involvement presenting with secondary cold agglutinin disease. Int J Lab Hematol 30: 444-445, 2008.
19. Kajiura D, Yamashita Y and Mori N: Diffuse large B-cell lymphoma initially manifesting in the bone marrow. Am J Clin Pathol 127: 762-769, 2007.

20. Chang H, Hung YS, Lin TL, Wang PN, Kuo MC, Tang TC, Wu JH, Dunn P and Shih LY: Primary bone marrow diffuse large B cell lymphoma: A case series and review. Ann Hematol 90: 791-796, 2011.

21. Sumi M, Ichikawa N, Shimizu I, Yotsumoto M, Ueno M and Kobayashi H: Primary diffuse large B-cell lymphoma of the bone marrow complicated with autoimmune hemolytic anemia and erythroid hypoplasia. Rinsho Ketsueki 48: 571-575, 2007 (In Japanese).

22. Hishizawa M, Okamoto K, Chonabayashi K, Kaneko H, Watanabe M and Tsudo M: Primary large B-cell lymphoma of the bone marrow. Br J Haematol 136: 351, 2007.

23. Wong KF, Chan JK, Ng CS, Chu YC, Li LP, and Chan $\mathrm{CH}$ : Large cell lymphoma with initial presentation in the bone marrow. Hematol Oncol 10: 261-271, 1992.

24. Jerusalem G, Beguin Y, Fassotte MF, Najjar F, Paulus P, Rigo P and Fillet G: Whole-body positron emission tomography using 18F-fluorodeoxyglucose for posttreatment evaluation in Hodgkin's disease and non-Hodgkin's lymphoma has higher diagnostic and prognostic value than classical computed tomography scan imaging. Blood 94: 429-433, 1999.

25. Zinzani PL, Fanti S, Battista G, Tani M, Castellucci P, Stefoni V, Alinari L, Farsad M, Musuraca G, Gabriele A, et al: Predictive role of positron emission tomography (PET) in the outcome of lymphoma patients. Br J Cancer 91: 850-854, 2004

26. Tai WM, Quah D, Yap SP, Tan SH, Tang T, Tay KW, Koo YX, Tao M, Quek R and Lim ST: Primary mediastinal large B-cell lymphoma: Optimal therapy and prognostic factors in 41 consecutive Asian patients. Leuk Lymphoma 52: 604-612, 2011.

27. Avilés A, Neri N, Fernández R, Huerta-Guzmán J and Nambo MJ: Randomized clinical trial to assess the efficacy of radiotherapy in primary mediastinal large B-lymphoma. Int J Radiat Oncol Biol Phys 83: 1227-1231, 2012.

28. Zhu YJ, Huang JJ, Xia Y, Zhao W, Jiang WQ, Lin TY, Huang HQ and Li ZM: Primary mediastinal large B-cell lymphoma (PMLBCL) in Chinese patients: Clinical characteristics and prognostic factors. Int J Hematol 94: 178-184, 2011.

29. Niscola P, Palombi M, Fratoni S, Perrotti A and de Fabritiis P: Primary diffuse large B-cell lymphoma of the bone marrow in a frail and elderly patient successfully treated with rituximab, cyclophosphamide, doxorubicin, vincristine, and prednisone. Blood Res 48: 296-297, 2013. 